\title{
Evaluation of temperature changes in the pulp chamber during polymerization of light-cured pulp-capping materials by using a VALO LED light curing unit at different curing distances
}

\author{
Selcuk SAVAS ${ }^{1}$, Murat S. BOTSALI², Ebru KUCUKYILMAZ ${ }^{1}$ and Tugrul SARI ${ }^{3}$ \\ ${ }^{1}$ Department of Pediatric Dentistry, Faculty of Dentistry, Izmir Katip Celebi University, Izmir, Turkey \\ ${ }^{2}$ Department of Pediatric Dentistry, Faculty of Dentistry, Selcuk University, Konya, Turkey \\ ${ }^{3}$ Department of Prostodontics, Faculty of Dentistry, Bezmialem Vakıf University, Istanbul, Turkey \\ Corresponding author, Ebru KÜÇÜKYILMAZ; E-mail: ebrukucukyilmaz@hotmail.com
}

\begin{abstract}
The aim of this study was to evaluate temperature changes in the pulp chamber during polymerization of four different pulpcapping materials using a LED-light-curing-unit in the contact and noncontact positions. A pulpal circulation mechanism was simulated to measure increases in temperature in four pulp-capping materials that were applied to the occlusal dentin surface. Two different distances were used between the tip of the unit and the material surface during polymerization; 0 and $2 \mathrm{~mm}$. The data were statistically analyzed using factorial-ANOVA, one-way-ANOVA, and Tukey's HSD test. There were statistically differences between contact and noncontact groups $(p<0.05)$. Contact groups produced significantly lower temperature rise compared with noncontact groups. The highest and lowest mean temperature increases were calculated for the Biner LC and the TheraCal LC, respectively. Considering the effects of temperature rising, the distance of the light curing units from restorations should not be overlooked as well as the types of the materials.
\end{abstract}

Keywords: Temperature rise, Pulp-capping materials, Light curing unit, Pulp chamber

\section{INTRODUCTION}

Preservation of pulpal health is one of the major objectives of restorative dentistry. Physical, chemical, biological, and thermal factors can affect dental pulp during operative procedures ${ }^{1-3)}$. Especially in deep cavities, the amount of remaining dentin thickness, types of pulp-capping material, and the heat generation during restorative procedures stand out as factors that affect the health of the pulp ${ }^{4-6)}$.

In deep cavities, the pulp tissue can be affected by bacterial toxins and thermal changes. In such cases, pulp-capping materials can be used to preserve the dentin-pulp complex against increasing temperature, show antibacterial activity, and to block bacterial transition in the pulp chamber ${ }^{1,7}$. Calcium hydroxide is the most widely used pulp-capping material in restorative dentistry, due to its ability to induce new dentin formation, antibacterial effect, and alkaline $\mathrm{pH}^{8}$. Despite its popularity, however, the physical properties of conventional calcium hydroxide such as water solubility, bond strength to dental hard tissues, and compressive strength, are relatively poor ${ }^{9}$. Due to these disadvantages, light-curing pulp-capping materials were developed to treat deep cavities and in case of pulpal exposure. But the heat generated during the polymerization of these materials could lead to an irreversible pulpal damage ${ }^{10}$. This increase in temperature could be originated from both the exothermic polymerization of the material and the energy absorbed from the light curing unit (LCU) ${ }^{11}$. Studies have shown that the type of LCU used is also a crucial factor affecting the amount of the generated heat ${ }^{12)}$. Recently, different types of light sources have been developed for use in clinical practice. Contemporary light emitting diode (LED) LCUs, which are more extensively in use compared to other light sources in restorative dentistry, have many advantages. They generate lesser heat, are resistant to overheating and, have longer lifetimes, and their light output decreases minimally over time ${ }^{13)}$.

The distance between LCU and material surface is another factor affecting increases in temperature ${ }^{144}$. For several reasons, in clinical conditions, it is not always possible to place the LCU in the same position. Differences among the anatomical shapes of teeth, the position of the teeth in dental arch, the depth of the restorations, and the design of the light source can all affect the position of LCU. Increased distances between the LCU and the material surface can cause insufficient polymerization of light-cured materials, due to reduced power ${ }^{15}$. Therefore, clinicians often prefer high-powered LED LCUs or longer irradiation time for durable restorations. However, increased light intensity and exposure time are risk factors that increase the temperature rise.

The aim of this study was to evaluate temperature changes in pulp chamber during the polymerization of four different light-curing pulp-capping materials using LED LCU in contact and noncontact positions.

Color figures can be viewed in the online issue, which is available at J-STAGE.

Received Oct 4, 2013: Accepted Jun 17, 2014

doi:10.4012/dmj.2013-274 JOI JST.JSTAGE/dmj/2013-274 


\section{MATERIALS AND METHODS}

The present study was approved by the Research Ethics Committee of the Izmir Katip Celebi University, under report no. 2014/61. One freshly extracted, intact, human mandibular second molar tooth was cleaned using a periodontal scaler and pumice slurry and stored in distilled water at room temperature until use. The roots of the tooth were removed by sectioning approximately $2 \mathrm{~mm}$ below the cemento-enamel junction and perpendicular to the long axis, using a water-cooled diamond disk. Additionally, the occlusal enamel of the tooth was completely removed to expose a flat dentin surface using the diamond disk. The pulpal remnants were removed and the thickness of occlusal dentin layer was measured using a precision caliper. Later, occlusal dentin layer was cautiously abraded using an 800grid silicone-carbide abrasive paper with a polishing machine (Minitech 233, Presi, Grenoble, France) in order to provide an occlusal dentin layer with a uniform thickness of $1 \mathrm{~mm}$ all over the occlusal area. A small notch was made at the edge of the dentin surface to remove the cured pulp-capping material from the tooth surface more easily. Finally, the tooth was attached to an apparatus which was originally designed and fabricated by us to simulate pulpal blood microcirculation (Fig. 1).

A standard infusion set (Gemed Medical Co., İstanbul, Turkey) with a 21-gauge (green) injector needle was attached to a distilled water reservoir $(1,000 \mathrm{~mL})$. The injector needle was shortened to $5 \mathrm{~mm}$ in length, and the tip of the needle (1 $\mathrm{mm}$ in length) was placed

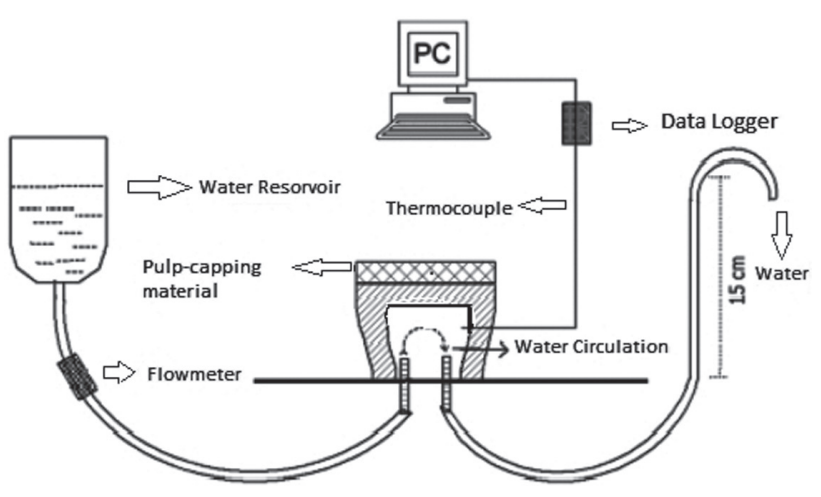

Fig. 1 Pulpal circulation mechanism. on a stainless steel metal plate through an artificial perforation and used as water inflow access. Another needle tip which was connected to a freestanding infusion tube was placed just contiguous to the first one to be used as water outflow exit and needle tips were fixed to the base plate using cyanoacrylate adhesive. The water flow rate of the system was set to a constant amount of $0.026 \mathrm{~mL} / \mathrm{min}$ by using a digital infusion flow meter (SK-600II infusion pump, SK Medical, Shenzhen, China) which was attached to the system. Distilled water at room temperature was used to simulate blood, and blood pressure in the pulp chamber used in this study was $15 \mathrm{~cm} \mathrm{H}_{2} \mathrm{O}$ (Fig. 1). The tooth was then mesially perforated using a diamond bur, in order to insert a 0.36-mm-diameter J-type thermocouple wire (Omega Engineering, Stamford, CT) into the pulp chamber to contact the occlusal wall of the pulp chamber. A silicone heat-transfer compound (ILC P/N 213414; Wakefield Engineering, Beverly, MA) was applied to the tip of the thermocouple wire, and the thermocouple wire was fixed at the adjusted position to stay in contact with the occlusal wall of the pulp chamber, using light-curing calcium hydroxide liner cement (Calcimol LC; Voco $\mathrm{GmbH}$, Cuxhaven, Germany). In this manner, the gap around the thermocouple wire was sealed to prevent leakage from the system. Light-curing glass-ionomer cavity liner cement (Glass liner; WP Dental $\mathrm{GmbH}$, Barmstedt, Germany) was used to fix the tooth onto the metal base plate. The thermocouple wire was connected to a data logger (XR440-M Pocket Logger; Pace Scientific, Mooresville, NC) and a computer to record the temperature increase data from inside the pulp chamber during the light activated curing process.

Increases in temperature were measured for four pulp-capping materials (ten measurements for each product): Ultra-Blend Plus, Calcimol LC, Biner LC, and TheraCal LC (Table 1). These materials (prepared according to the manufacturer's instructions) were applied to the occlusal dentin surface to be $1 \mathrm{~mm}$ thick and polymerized with an LED LCU by one operator. To control this thickness, a 1-mm high metal ring was used. The light output of the LCU was measured with a radiometer specifically designed for LED before beginning and after each ten measurements. Details of the LCU parameters and curing modes are shown in Table 2. Two different distances between the tip of the unit and the light-cured pulp-capping material surfaces during polymerization were evaluated; $0 \mathrm{~mm}$ (with the

Table 1 Materials employed in the study

\begin{tabular}{lcc}
\hline & Manufacturer & Product Description \\
\hline Ultra-Blend Plus & Ultradent Products Inc, South Jordan, UT, USA & Light curing calcium hydroxide \\
Calcimol LC & Voco GmbH, Cuxhaven, Germany & Light curing calcium hydroxide \\
Biner LC & Meta Biomed Inc, Horsham, PA & Light curing calcium hydroxyphosphaste \\
TheraCal LC & Bisco Inc, Schamburg, IL, USA & Light curing resin-modified calcium silicate \\
\hline
\end{tabular}


Table 2 Light curing unit used in this study

\begin{tabular}{|c|c|c|c|c|c|}
\hline LCU & Manufacturer & Lens Diameter & Curing Mode & Light Intensity & Wavelength \\
\hline $\begin{array}{l}\text { VALO LED light } \\
\text { curing unit }\end{array}$ & $\begin{array}{l}\text { Ultradent Products Inc, } \\
\text { South Jordan, UT, USA }\end{array}$ & $9.6 \mathrm{~mm}$ & Standard Power & $1000 \mathrm{~mW} / \mathrm{cm}^{2}$ & $395-480 \mathrm{~nm}$ \\
\hline
\end{tabular}

tip touching the polyester strip) and $2 \mathrm{~mm}$. The surfaces of the materials were smoothed with a strip of polyester that was removed before polymerization. To standardize this distance, a $2-\mathrm{mm}$ high metal ring was used as a spacer, and the light-curing unit was placed over this ring. For each sample, the initial temperature and the maximum temperature increase were calculated. Moreover, a group without any lining material has been added to the study as a control group. For these groups two different distances were used $0 \mathrm{~mm}$ and $2 \mathrm{~mm}$ and temperature increase were calculated.

The sampling rate of the data logger was set to one sample every $2 \mathrm{~s}$ for a recording duration, starting with light application for approximately $40 \mathrm{~s}$, until the temperature started to decrease. The collected data, in both tabular and graphic form, were monitored in real time and transferred to the computer. Later, the difference between the initial and highest temperature readings $(\Delta \mathrm{t})$ was taken.

\section{Statistical analysis}

Prior to the data collection, a power analysis was performed with $\mathrm{G}^{*}$ Power 3.0.10 (Franz Faul, ChristianAlbrechts-Universität, Kiel, Germany) to estimate the sample size. The analysis indicated that a group sample size of 9 would result in more than $80 \%$ power (actual power $=96 \%$; critical $\mathrm{F}=5.59$; noncentrality parameter $\lambda=18.79$ ) for numerator d.f. $=1$ while a group sample size of 10 would give more than $80 \%$ power (actual power $=97 \%$; critical $\mathrm{F}=5.19$; noncentrality parameter $\lambda=54.52$ ) for numerator $\mathrm{d} . \mathrm{f}=4$ to detect significant differences with 1.40 and 2.30 effect sizes, respectively, and at $\alpha=0.05$ significance level.

Increased temperature data were analyzed using the IBM SPSS Statistics version 20.0 statistical package (SPSS, Chicago, IL, USA). The dependent variable across groups was examined in terms of existence normality assumption by performing a Shapiro-Wilk test and Levene's test for constant homogeneous variances.

A factorial ANOVA design was used to test the main effects and the interaction effect of the factors such as material type and curing distance. A statistically significant interaction effect was found, and follow-up tests were run, using combined factors within a one-way ANOVA, followed by pairwise comparisons between the combined factor levels to determine which combinations contributed significantly to the interaction.

\section{RESULT}

In evaluation of curing distance factor, independently of
Table 3 Temperature rises (in degrees celcius) for distance factor in pulp chambers during polymerization of the materials by the curing units and results of ANOVA, independent of other factors

\begin{tabular}{lll}
\hline \multicolumn{1}{c}{ Distance Groups } & $\mathrm{n}$ & Mean \pm SD \\
\hline Noncontact Groups & 40 & $9.38^{\mathrm{a}} \pm 0.89$ \\
Contact Groups & 40 & $7.51^{\mathrm{b}} \pm 1.10$ \\
\hline
\end{tabular}

*The letters sign statistically different groups $(p<0.05)$

Table 4 Temperature rises (in degrees celcius) for pulpcapping materials factor in pulp chambers during polymerization by the light curing unit and results of ANOVA, independent of other factors

\begin{tabular}{ccc}
\hline Pulp Capping Materials & $\mathrm{n}$ & Mean \pm SD \\
\hline Ultra-Blend Plus & 20 & $8.78^{\mathrm{a}} \pm 0.96$ \\
Calcimol LC & 20 & $8.06^{\mathrm{b}} \pm 0.96$ \\
Biner LC & 20 & $9.41^{\mathrm{c}} \pm 1.41$ \\
TheraCal LC & 20 & $7.53^{\mathrm{b}} \pm 1.34$ \\
Control Group & 20 & $11.53^{\mathrm{d}} \pm 0.72$ \\
\hline
\end{tabular}

*The letters sign statistically different groups $(p<0.05)$

others factors, the mean temperature rises of the contact and noncontact groups are presented in Table 3. The temperature increases of the noncontact groups were significantly higher than those of the contact groups $(p<0.05)$.

For pulp-capping materials, the highest temperature rise $\left(9.41^{\circ} \mathrm{C} \pm 1.41^{\circ} \mathrm{C}\right)$ and the lowest temperature rise $\left(7.53^{\circ} \mathrm{C} \pm 1.34^{\circ} \mathrm{C}\right)$ were calculated for Biner $\mathrm{LC}$ and the TheraCal LC, respectively. Overall, while there was no significant difference between the TheraCal LC and the Calcimol LC groups $(p>0.05)$, there were statistically significant differences among all the other groups $(p<0.05)$ (Table 4). Table 5 and Figure 2 present the mean temperature increases for all the pulp-capping materials and the distance factors. 
Table 5 Temperature rises (in degrees celcius) for pulpcapping materials factor and distance factors in pulp chambers during polymerization by the light curing unit and results of ANOVA

\begin{tabular}{lcr}
\hline & $\mathrm{n}$ & \multicolumn{1}{c}{ Mean \pm SD } \\
\hline Ultra-Blend Plus-Noncontact & 10 & $9.31^{\mathrm{a}} \pm 0.55$ \\
Ultra-Blend Plus-Contact & 10 & $8.25^{\mathrm{b}} \pm 1.02$ \\
Calcimol LC-Noncontact & 10 & $8.88^{\mathrm{ab}} \pm 0.48$ \\
Calcimol LC-Contact & 10 & $7.24^{\mathrm{c}} \pm 0.47$ \\
Biner LC-Noncontact & 10 & $10.58^{\mathrm{d}} \pm 0.70$ \\
Biner LC-Contact & 10 & $8.24^{\mathrm{b}} \pm 0.84$ \\
TheraCal LC-Noncontact & 10 & $8.75^{\mathrm{a}} \pm 0.35$ \\
TheraCal LC-Contact & 10 & $6.32^{\mathrm{e}} \pm 0.64$ \\
Control Group-Noncontact & 10 & $12.08^{\mathrm{f}} \pm 0.45$ \\
Control Group-Contact & 10 & $10.98^{\mathrm{d}} \pm 0.47$ \\
\hline
\end{tabular}

*The letters sign statistically different groups $(p<0.05)$

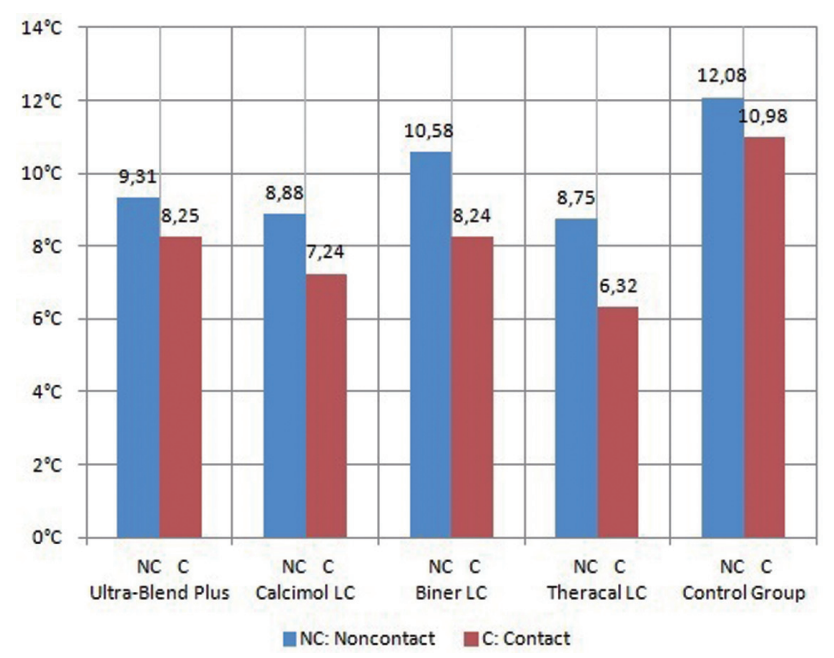

Fig. 2 The mean temperature rises for all groups.

\section{DISCUSSION}

An increase in temperature during operative procedures can affect the health of vital pulp ${ }^{16}$. Several factors can affect temperature increase in pulp chamber, such as cavity preparation procedures, bleaching of the teeth, laser light applications, polishing of dental materials, and polymerization of light-cured materials ${ }^{17-19)}$. Polymerization-induced temperature increase depends on two factors: the crucial factor causing temperature rise during the polymerization of light-cured materials is the heat generated by LCU. The exothermic polymerization of the material is the secondary factor ${ }^{11)}$. This literature information is compatible with the results of current study. According the results of the control group, when the light curing unit was applied without any lining material, an excessive heat was generated. Although exothermic reaction of the resin based materials is generating some heat, these lining materials primarily prevent the conduction of the heat generated by LCU to the pulp chamber.

In addition, various factors, such as the light intensity of the LCU, the amount of remaining dentin thickness, the composition of the restorative materials, the distance between LCU and material surface, the position of LCU, and exposure time can affect the extent of the increase in temperature during the polymerization process ${ }^{14,20-22)}$. Among these factors, the distance between the LCU and the restoration surface arises as an important factor for the success of the restoration. Studies reported that, an increase in distance of the light source from the materials surface results in a decrease in microhardness and the degree of conversion of the restorative materials for all types of light sources studied ${ }^{23,24)}$.Thus, in this study, we aimed to determine the effects of curing distance and types of pulp-capping material on temperature increase in the pulp chamber.

Over the years, the effects of external heat application on pulp tissues have been investigated in many studies ${ }^{6,19,25)}$. However, the level of temperature increase that can be tolerated by dental tissues remains unknown. In their animal study, Zach and Cohen ${ }^{25)}$ found that a $5.6^{\circ} \mathrm{C}$ temperature increase in the pulp chamber induced necrosis of the pulp in $15 \%$ of teeth. Temperature increases of $11.1^{\circ} \mathrm{C}$ and $16.6^{\circ} \mathrm{C}$ induced necrosis of the pulp in $60 \%$ and $100 \%$ of teeth, respectively. In addition, Eriksson et al. ${ }^{26)}$ suggested that duration of temperature increase is an important factor for creating permanent change in pulp tissues. The authors reported that $42^{\circ} \mathrm{C}$ is a critical temperature when sustained for one min duration.

In previous studies, different techniques were used to evaluate temperature increase, such as calorimeter, thermocouple, differential thermal analysis, and infrared cameras. In the current study, the thermocouple technique was selected to measure temperature changes during polymerization of pulp-capping materials due to its reliable and precise results ${ }^{27-29)}$.

Pulp microcirculation plays an important role in elimination temperature increases when the pulp tissue is affected by a thermal stimulus ${ }^{20)}$. When pulpal temperatures exceed $43^{\circ} \mathrm{C}$, the pulpal neuron is stimulated and the blood circulation of the pulp chamber increases, so it is a mechanism for heat dissipation ${ }^{30}$. A few studies in the literature have evaluated the role of pulp microcirculation as a cooling agent in the thermal behavior of the dentin pulp complex. In most in vitro studies, the treated teeth were placed in a water tank containing standing water at $37^{\circ} \mathrm{C}^{31,32)}$. In this study, in order to simulate the circulation of the pulp chamber, a pulpal circulation mechanism was created. This mechanism allowed water to circulate within the pulp 
chamber at a defined flow rate and pressure to simulate a clinical case. These mechanisms provide more realistic results, as simulating blood circulation in the pulp chamber with water flow reflects clinical conditions better than without water flow.

Comparative studies have demonstrated that the amount of remaining dentin thickness plays an important role in protecting the pulp chamber from temperature increase ${ }^{33,34)}$. In the literature, while same group of teeth were used in some studies ${ }^{2,19)}$, only one tooth was used in the others ${ }^{12,14,32)}$. Studies that used the same group of teeth showed that some differences in tooth morphology such as enamel and dentinal structure and thickness that can cause the differences in the thermal conductivity of the teeth tested ${ }^{3,27,33)}$. For this reason, to standardize residual dentine thickness, one permanent second molar tooth was used for each group. This procedure provided to eliminate any possible variables of teeth that might manifest as differences in thermal conductivity and specific heat.

According to the results of this study, TheraCal LC had the lowest mean temperature increase of all the other pulp capping materials, independent of distance factor. The reason for the low temperature increase with TheraCal LC might be because its content is different from the other materials. While all the materials contain calcium hydroxide, only TheraCal LC contains resin modified calcium silicate filler. Calcium silicate has a low specific heat capacity (C) compared with calcium hydroxide which is the content of the other materials that used in this study ${ }^{35}$. The specific heat capacity is directly proportional with the thermal conductivity of the materials. So, a material which has a low specific heat capacity shows high thermal insulation properties. Because of these insulation characteristics, calcium silicate, has been used over the years as an insulation material in many industrial branches ${ }^{36,37)}$. Therefore, calcium silicate's high temperature insulation characteristic gives TheraCal LC its insulation ability.

In two different positions of the light source, the difference between the amounts of temperature delivered to the pulp tissue during polymerization of each pulp-capping material is as follows: Ultra Blend Plus: $1.06^{\circ} \mathrm{C}$, Calcimol LC: $1.64^{\circ} \mathrm{C}$, Biner $\mathrm{LC}: 2.34^{\circ} \mathrm{C}$, and Theracal $\mathrm{LC}: 2.43^{\circ} \mathrm{C}$. The reason for this difference between the materials is thought to be caused by the variation in the compositions and content of the materials. In evaluating distance factor, independent of pulp-capping materials factor, there were statistically significant differences between contact and non-contact groups, and the temperature increase observed in the noncontact groups was significantly higher than that of the contact groups. These differences can be related to different power densities between the two curing distances. In previous studies, it has been found that when the curing distance between the LCU and the restoration surface increases, the temperature increase is lower. The highest temperature increase was found when the LCU was closest to the restoration surface ${ }^{38)}$. For this purpose, in this study, we aimed to find the maximum temperature at which that might occur. The light source used in this study is a high-powered LED LCU for the polymerization of light-cured dental materials. Its glass lens provides the ability to focus and collimate the light intensity, resulting in minimally decreased power density with increased distance. Its light intensity reaches the highest value at a distance of $2 \mathrm{~mm}$, after which it decreases again ${ }^{39)}$. The light intensity of the LCU influences the temperature increase caused by the polymerization process of restorative materials. When the light intensity that reaches the restoration material surfaces increases, there may also be an increase in temperature rise. Although the high light output and collimated beam is an advantage for an adequate polymerization ${ }^{40)}$, these properties of LCU may have led to the high temperature increase in this study, especially at $2 \mathrm{~mm}$.

This in vitro study demonstrated that all the results were above the critical point of $5.6^{\circ} \mathrm{C}$, which was reported by Zach and Cohen ${ }^{25)}$. Although we used the pulpal microcirculation mechanism to simulate clinical situations, other mechanisms, such as fluid motions in dentinal tubules and the surrounding periodontal tissues of the teeth, were not considered. These regulatory mechanisms might limit the intrapulpal temperature increase. However, clinicians should be aware of the potential thermal hazard of the light curing units to the pulp. Applying the self-cure lining materials in deep cavities, decreasing the time of curing period, choosing the correct type LCU, using the LCU with the right power density and polymerization mode, setting the correct distance between the LCU and restoration surface, may maintain the health of the pulp tissue. However, it must be emphasized that the results of this study cannot be directly extrapolated to the clinical situation. The present study was a laboratory investigation and the experiment was performed in the room temperature. Different results might be achieved with intra-oral conditions.

\section{CONCLUSIONS}

Within the limitations of this study, the following conclusions were drawn:

- The distance of LCU from the restoration surface affect temperature increase in the pulp chamber.

- TheraCal LC, with low temperature changes during polymerization, might be preferable as an indirect pulp-capping material in deep cavities.

\section{REFERENCES}

1) Modena KC, Casas-Apayco LC, Atta MT, Costa CA, Hebling J, Sipert CR, Navarro MF, Santos CF. Cytotoxicity and biocompatibility of direct and indirect pulp capping materials. J Appl Oral Sci 2009; 17: 544-554.

2) Kivanc BH, Arisu HD, Ulusoy OI, Saglam BC, Görgül G. Effect of light-activated bleaching on pulp chamber temperature rise: an in vitro study. Aust Endod J 2012; 38: 76-79.

3) Langeland K. Effect of various procedures on the human dental pulp. Oral Surg Oral Med Oral Pathol 1961; 14: 210- 
233.

4) Neelakantan P, Rao CV, Indramohan J. Bacteriology of deep carious lesions underneath amalgam restorations with different pulp-capping materials-an in vivo analysis. J Appl Oral Sci 2012; 20: 139-145.

5) Murray PE, Smith AJ, Windsor LJ, Mjor IA. Remaining dentine thickness and human pulp responses. Int Endod J 2003; 36: 33-43.

6) Wataha JC, Lockwood PE, Lewis JB, Rueggeberg FA, Messer RL. Biological effects of blue light from dental curing units. Dent Mater 2004; 20: 150-157.

7) Foreman PC, Barnes IE. Review of calcium hydroxide. Int Endod J 1990; 23: 283-297.

8) Cohenca N, Paranjpe A, Berg J. Vital pulp therapy. Dent Clin North Am 2013; 57: 59-73.

9) Cox CF, Subay RK, Ostro E, Suzuki S, Suzuki SH. Tunnel defects in dentin bridges: their formation following direct pulp capping. Oper Dent 1996; 21: 4-11.

10) Smail SR, Patterson CJ, McLundie AC, Strang R. In vitro temperature rises during visible-light curing of a lining material and a posterior composite. J Oral Rehabil 1988; 15: 361-366.

11) Lloyd CH, Joshi A, McGlynn E. Temperature rises produced by light sources and composites during curing. Dent Mater 1986; 2 : 170-174.

12) Hannig M, Bott B. In-vitro pulp chamber temperature rise during composite resin polymerization with various lightcuring sources. Dent Mater 1999; 15: 275-281.

13) Moon HJ, Lee YK, Lim BS, Kim CW. Effects of various light curing methods on the leachability of uncured substances and hardness of a composite resin. J Oral Rehabil 2004; 31: 258264.

14) Uzel A, Buyukyilmaz T, Kayalioglu M, Uzel I. Temperature rise during orthodontic bonding with various light-curing units-an in vitro study. Angle Orthod 2006; 76: 330-334.

15) Bennett AW, Watts DC. Performance of two blue lightemitting-diode dental light curing units with distance and irradiation-time. Dent Mater 2004; 20: 72-79.

16) Stanley HR, Human pulpal response to Operative Procedures 2nd Edtn, p.15. Storter Printing Company, Gainesville, FL.

17) Attrill DC, Davies RM, King TA, Dickinson MR, Blinkhorn AS. Thermal effects of the Er:YAG laser on a simulated dental pulp: a quantitative evaluation of the effects of a water spray. J Dent 2004; 32: 35-40.

18) Schneider LF, Consani S, Correr-Sobrinho L, Correr AB, Sinhoreti MA. Halogen and LED light curing of composite: temperature increase and Knoop hardness. Clin Oral Investig 2006; 10: 66-71.

19) Coutinho DS, Silveira L Jr, Nicolau RA, Zanin F, Brugnera A Jr. Comparison of temperature increase in in vitro human tooth pulp by different light sources in the dental whitening process. Lasers Med Sci 2009; 24: 179-185.

20) Asmussen E, Peutzfeldt A. Temperature rise induced by some light emitting diode and quartz-tungsten-halogen curing units. Eur J Oral Sci 2005; 113: 96-98.

21) Loney RW, Price RB. Temperature transmission of highoutput light-curing units through dentin. Oper Dent 2001; 26: 516-520.

22) Al-Qudah A, Mitchell CA, Biagioni PA, Hussey DL. Effect of composite shade, increment thickness and curing light on temperature rise during photocuring. J Dent 2007; 35: 238-
245.

23) Cekic-Nagas I, Egilmez F, Ergun G. The effect of irradiation distance on microhardness of resin composites cured with different light curing units. Eur J Dent 2010; 4: 440-446.

24) Rode KM, Kawano Y, Turbino ML. Evaluation of curing light distance on resin composite microhardness and polymerization. Oper Dent 2007; 32: 571-578.

25) Zach L, Cohen G. Pulp response to externally applied heat. Oral Surg Oral Med Oral Pathol 1965; 19: 515-530.

26) Eriksson A, Albrektsson T, Grane B, McQueen D. Thermal injury to bone. A vital microscopic description of heat effects. Int J Oral Surg 1982; 11: 115-121.

27) Guiraldo RD, Consani S, Lympius T, Schneider LF, Sinhoreti MA, Correr-Sobrinho L. Influence of the light curing unit and thickness of residual dentin on generation of heat during composite. J Oral Sci 2008; 50: 137-142.

28) Lloyd CH. A differential thermal analysis (DTA) for the heats of reaction and temperature rises produced during the setting of tooth coloured restorative materials. J Oral Rehabil 1984; 11: 111-121.

29) Usumez A, Ozturk N. Temperature increase during resin cement polymerization under a ceramic restoration: effect of type of curing unit. Int J Prosthodont 2004; 17: 200-204.

30) Raab WH. Temperature related changes in pulpal microcirculation. Proc Finn Dent Soc1992; 88: 469-479.

31) Michalakis K, Pissiotis A, Hirayama H, Kang K, Kafantaris N. Comparison of temperature increase in the pulp chamber during the polymerization of materials used for the direct fabrication of provisional restorations. J Prosthet Dent 2006; 96: 418-423.

32) Yazici AR, Müftü A, Kugel G, Perry RD. Comparison of temperature changes in the pulp chamber induced by various light curing units, in vitro. Oper Dent 2006; 31: 261-265.

33) Secilmis A, Bulbul M, Sari T, Usumez A. Effects of different dentin thicknesses and air cooling on pulpal temperature rise during laser welding. Lasers Med Sci. 2013; 28: 167-170.

34) Dogan A, Hubbezoglu I, Dogan OM, Bolayir G, Demir H. Temperature rise induced by various light curing units through human dentin. Dent Mater J 2009; 28: 253-260.

35) Bentz DP, and Prasad KR, "Thermal Performance of Fire Resistive Materials I. Characterization of Fire Resistive Materials with Respect to Thermal Performance Models" NISTIR 7401, U.S. Department of Commerce, February 2007.

36) Zheng Q, Wang W. Calcium silicate based high efficiency thermal insulation. Brit Ceram Trans 2000; 99: 187-190.

37) Mojumdar SC, Raki L, Mathis N, Schimdt K, Lang S. Thermal, spectral and AFM studies of calcium silicate hydrate-polymer nanocomposite material. J Therm Anal Calorim 2006; 85: 119-124.

38) Ebenezar AVR, Anilkumar R, Indira R, Ramachandran S, Srinivasan MR. Comparison of temperature rise in the pulp chamber with different light curing units: An in-vitro study. J Conserv Dent 2010; 13: 132-135.

39) Valo, Ultradent Products. White Paper, 2012: htpp//:www. valo-led.com

40) Knezevic A, Tarle Z, Meniga A, Sutalo J, Pichler G, Ristic M. Degree of conversion and temperature rise during polymerization of composite resin samples with blue diodes. J Oral Rehabil 2001; 28; 586-591. 